BMC

Veterinary Research

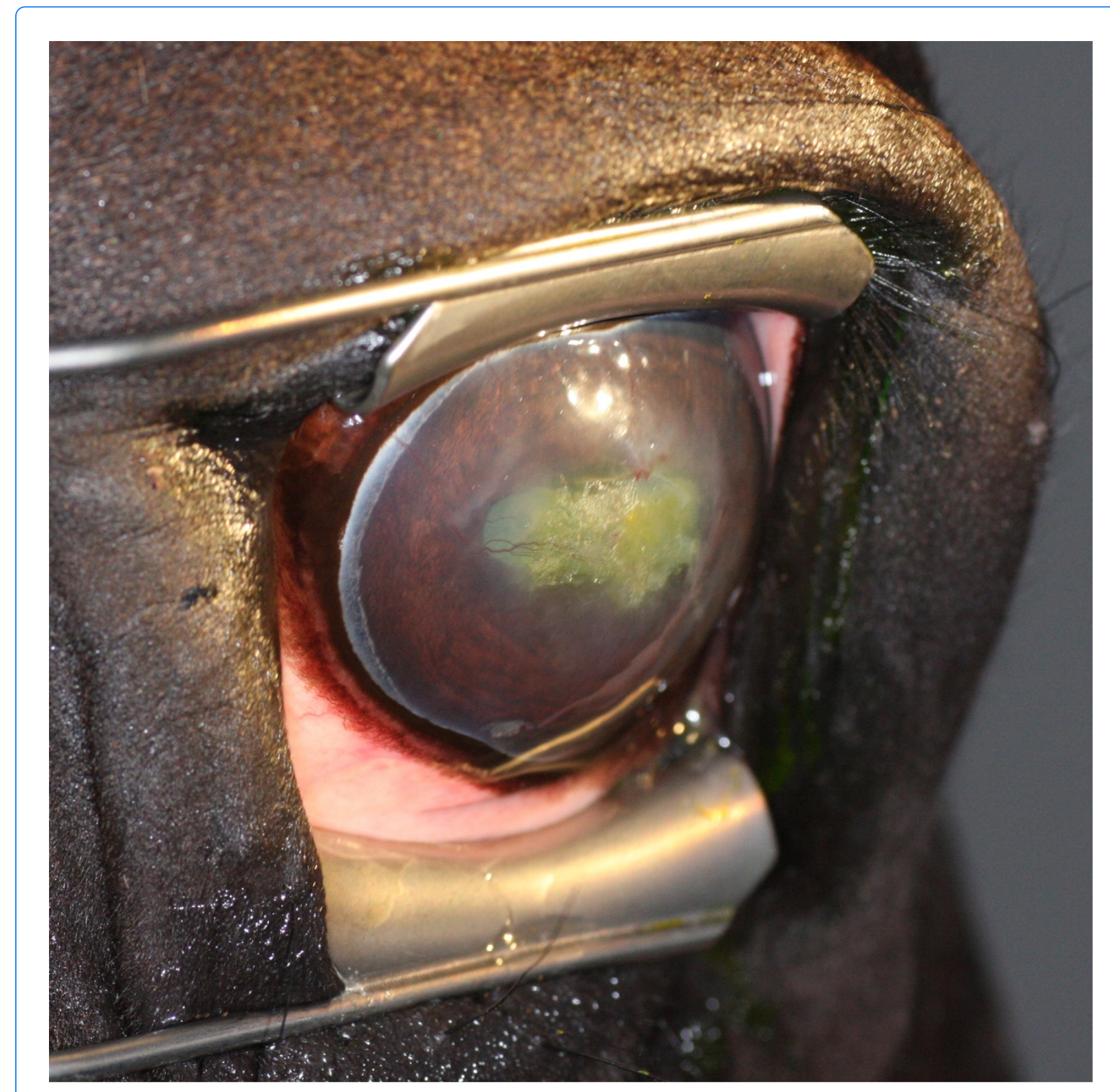

\title{
Corneal cross-linking in 9 horses with ulcerative keratitis
}

Hellander-Edman et al. 


\title{
Corneal cross-linking in 9 horses with ulcerative keratitis
}

Anna Hellander-Edman ${ }^{1 *}$, Karim Makdoumi ${ }^{2}$, Jes Mortensen ${ }^{2}$ and Björn Ekesten ${ }^{3}$

\begin{abstract}
Background: Corneal ulcers are one of the most common eye problems in the horse and can cause varying degrees of visual impairment. Secondary infection and protease activity causing melting of the corneal stroma are always concerns in patients with corneal ulcers. Corneal collagen cross-linking $(\mathrm{CXL})$, induced by illumination of the corneal stroma with ultraviolet light (UVA) after instillation of riboflavin (vitamin B2) eye drops, introduces crosslinks which stabilize melting corneas, and has been used to successfully treat infectious ulcerative keratitis in human patients. Therefore we decided to study if CXL can be performed in sedated, standing horses with ulcerative keratitis with or without stromal melting.

Results: Nine horses, aged 1 month to 16 years (median 5 years) were treated with a combination of CXL and medical therapy. Two horses were diagnosed with mycotic, 5 with bacterial and 2 with aseptic ulcerative keratitis. A modified Dresden-protocol for CXL could readily be performed in all 9 horses after sedation. Stromal melting, diagnosed in 4 horses, stopped within 24 h. Eight of nine eyes became fluorescein negative in 13.5 days (median time; range 4-26 days) days after CXL. One horse developed a bacterial conjunctivitis the day after CXL, which was successfully treated with topical antibiotics. One horse with fungal ulcerative keratitis and severe uveitis was enucleated 4 days after treatment due to panophthalmitis.

Conclusions: CXL can be performed in standing, sedated horses. We did not observe any deleterious effects attributed to riboflavin or UVA irradiation per se during the follow-up, neither in horses with infectious nor aseptic ulcerative keratitis. These data support that CXL can be performed in the standing horse, but further studies are required to compare $C X L$ to conventional medical treatment in equine keratitis and to optimize the CXL protocol in this species.
\end{abstract}

Keywords: Equine, Horse, Keratitis, Corneal ulceration, Cross-linking, Cross linking, Collagen, CXL, UVA, Riboflavin, Stromal melting

\section{Background}

Corneal ulcers are one of the most common eye problems in the horse and can cause varying degrees of visual impairment or even blindness [1,2]. Secondary infection and protease activity causing melting of the corneal stroma are always concerns for the clinician, even in horses with superficial ulcers. Exposure of a corneal ulcer to organisms from both the ocular surface and the environment may result in secondary infection, which combined with infiltrating polymorphonuclear leukocytes, stimulates production and activity of proteolytic

\footnotetext{
* Correspondence: anna.hellander.edman@slu.se

1 Department of Animal Environment \& Health, Swedish University of

Agricultural Sciences, PO Box 234, SE-532 24 Skara, Sweden

Full list of author information is available at the end of the article
}

enzymes and subsequent corneal melting $[1,3,4]$. Conventional medical treatment of the melting process involves controlling infection with antibiotics and managing pain. However, antibiotic treatment of equine corneal ulcers can lead to acquired antibiotic resistance and selective propagation of resistant bacteria [5,6].

The term cross-linking refers to the formation of covalent bonds between long chained molecules. Intermolecular cross-linking increases the rigidity of materials and is also a natural part in the normal aging of the corneal stroma $[7,8]$. Corneal cross-linking (CXL) is induced by introducing riboflavin (vitamin B2) to the cornea and illuminating it with ultraviolet light (UVA). Riboflavin absorbs UVA and visible light, producing reactive oxygen species (ROS) [9]. In the cornea, ROS

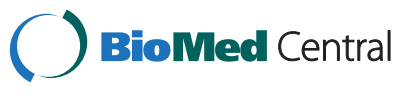


increase the number of covalent bonds among stromal collagen molecules [10], which enhances the biomechanical rigidity of the cornea [11-14]. Furthermore, CXL changes molecular structures within the cornea to prevent proteolytic enzymes from binding to specific cleavage sites, decreasing the efficacy of collagen degrading enzymes [15]. Thus, through increasing biomechanical strength and decreasing proteolysis, CXL has been demonstrated to be effective in cases of keratoconus and melting ulcers in humans $[16,17]$.

Riboflavin has been used for inactivation of pathogens in blood products [18], due to its ability to induce strand cleavage of DNA and RNA, thus interfering with the replication of pathogenic microorganisms $[19,20]$. In its application to the cornea, CXL has been documented to exert antimicrobial effects, both in vitro $[21,22]$ and in vivo [23-26]. The specific mechanisms remain to be elucidated, but it is possible that the increased resistance of collagen to degradative enzymes, as well as a direct antimicrobial effect of ROS may be involved [27].

In human eyes, cross-linking of the cornea appears to be a safe procedure. However, two potential risks to the eye from UVA exposure have to be considered: direct damage to corneal cells and intraocular structures from UVA irradiation, and indirect damage to all regional cells from ROS [28]. Riboflavin limits the potential for direct damage, as it limits radiant transmission to deeper ocular structures by absorbing UVA-light. In human, porcine, and rabbit corneas, damage to keratocytes occurs to a depth of $300 \mu \mathrm{m}$ with surface irradiance of $3 \mathrm{~mW} / \mathrm{cm}^{2}$ [29-31], thus it is recommended that CXL only be conducted when corneal thickness exceeds $400 \mu \mathrm{m}$. This provides a margin of safety that avoids direct damage to the corneal endothelium and intraocular structures $[32,33]$. The loss of stromal keratocytes in the illuminated area can be accepted, because it is temporary to current knowledge and repopulation occurs during 6 months after the UVA illumination [34,35].

Since stromal ulcerative keratitis is a common condition in the horse, frequently associated with secondary infection and melting of the stroma, we decided to test whether it was possible to perform CXL in sedated, standing horses. We also wanted to know if equine stromal ulcerative keratitis with and without melting would heal after treatment with a combination of CXL and medical therapy.

\section{Results}

All horses were diagnosed with stromal ulcerative keratitis with leukocyte infiltrates surrounding the ulcers (Table 1). Four horses showed clinical signs of corneal melting. Microbiological cultures in 7 out of 9 horses were positive for bacteria or fungi.
CXL could be performed in all 9 horses. Removal of a narrow zone of the surrounding corneal epithelium, instillation of riboflavin eye drops and exposure of the ulcerated area to UVA light was well tolerated by the sedated horses. Each treatment session, from sedation to completion of the CXL (including sampling for cytology and microbiology), took approximately two hours. Instillation of riboflavin can readily be performed by one person, whereas other parts of the procedure require both a veterinarian and a nurse.

Eight of nine eyes treated with CXL combined with topical and systemic medical treatment (as described in the Methods section), healed with light stromal scarring (Figure 1). Within 3 days, all of these eight eyes showed improvement of clinical signs. The healing process of the stromal ulcers after CXL followed a similar pattern with respect to the reduction of inflammatory signs, including reduced signs of ocular pain, decrease in corneal oedema and ciliary injection and less aqueous flare and inflammatory cells in the anterior chamber. The stromal melting had stopped when re-examined the day after treatment. In 2-4 days, a granular appearance of the denuded stromal tissue could be observed and in some cases a rejection of necrotic mucoid tissues followed (Figure 2). Ingrowth of blood vessels to the ulcerated area and regeneration of the corneal stroma and reepithelialization could be observed. Eight of nine eyes became fluorescein negative in 13.5 days (median time; range 4-26 days) after CXL (Table 2).

CXL treatment failed in one of the two horses with fungal ulcerative keratitis (Table 1). This horse, horse no. 1 , developed panophthalmitis during 4 days after the CXL and the eye was enucleated. Histopathology of the eye showed keratomalacia with ulcerations of Descemet's membrane and infiltration of fungal hyphae into the anterior chamber.

In horse no. 2, neither fungal hyphae nor bacteria were observed on cytology four days after CXL. The two stromal ulcers in this horse became fluorescein negative in 5 and 9 days after CXL, respectively (Figure 3).

Horse no. 3, which had streptococcal keratitis, was negative on corneal culture and no bacteria were present on cytology 5 days after CXL, despite the lack of topical antimicrobial treatment after CXL (Figure 1).

One patient, horse no. 2, developed purulent conjunctivitis the day after CXL treatment. Bacterial culture from the conjunctiva was positive for Enterobacter and the conjunctivitis resolved after topical treatment with chloramphenicol.

\section{Discussion}

CXL could readily be performed in all 9 horses under sedation and standing surgery. The procedure is rather timeconsuming to perform compared to medical treatment 
Table 1 Details of 9 horses treated with CXL and medical treatment for stromal ulcerative keratitis

\begin{tabular}{|c|c|c|c|c|c|c|c|c|c|c|}
\hline Horse & Breed & $\begin{array}{l}\text { Sex } \\
\text { and age }\end{array}$ & $\begin{array}{l}\text { Disease } \\
\text { history }\end{array}$ & $\begin{array}{l}\text { Topical medication } \\
\text { pre CXL }\end{array}$ & $\begin{array}{l}\text { Stromal ulcer size; depth } \\
\text { pre CXL }\end{array}$ & $\begin{array}{l}\text { Stromal } \\
\text { melting }\end{array}$ & Comments & $\begin{array}{l}\text { Microbes on cytology and } \\
\text { in culture pre CXL }\end{array}$ & $\begin{array}{l}\text { Fluor. neg. } \\
\text { post CXL }\end{array}$ & $\begin{array}{l}\text { Follow } \\
\text { up time }\end{array}$ \\
\hline 1 & Mixed breed pony & G 6 yr & $4 w$ & $\begin{array}{l}\text { Fucidic acid } 1 \mathrm{w}, \\
\text { chloramphenicol } \\
2 \mathrm{w} \text {, natamycin } 1 \mathrm{w}\end{array}$ & $5 \times 5 \mathrm{~mm} ; 1 / 3$ & no & Hypopyon & $\begin{array}{l}\text { Abundant fungal hyphae/ Yeast } \\
\text { overgrowth, mixed bacteria }\end{array}$ & Enucl. & $\mathrm{n} / \mathrm{a}$ \\
\hline 2 & Swedish Warmblood & G $5 \mathrm{yr}$ & $4 \frac{1}{2} W$ & $\begin{array}{l}\text { Fucidic acid } 1 \mathrm{~W}, \\
\text { chloramphenicol- } \\
\text { ciprofloxacin } 2 \frac{1}{2} \mathrm{~W} \text {, } \\
\text { natamycin } 1 \mathrm{~W}\end{array}$ & $4 \times 4 \mathrm{~mm} ; 1 / 37 \times 7 \mathrm{~mm} ; 1 / 3$ & yes & & $\begin{array}{l}\text { Abundant fungal hyphae/ } \\
\text { Scedosporium spp. }\end{array}$ & $9 d$ & $19 \mathrm{mo}$ \\
\hline 3 & Warmblood Trotter & $\mathrm{F} 1 \mathrm{yr}$ & $1 \mathrm{w}$ & Chloramphenicol $1 \mathrm{w}$ & $10 \times 10 \mathrm{~mm} ; 2 / 3$ & yes & $\begin{array}{l}\text { Extensive cellular infiltration. } \\
\text { Severe purulent discharge }\end{array}$ & $\begin{array}{l}\text { Abundant coccoid bacteria/ } \\
\text { B-hem. Streptococcus }\end{array}$ & $20 d$ & $12 \mathrm{mo}$ \\
\hline 4 & Islandic horse & S $2 \mathrm{yr}$ & $<1 w$ & Chloramphenicol < 1w & $8 \times 8 \mathrm{~mm} ; 2 / 3$ & no & Hypopyon & $\begin{array}{l}\text { Sparse coccoid bacteria/ } \\
\text { B-hem. Streptococcus }\end{array}$ & $9 d$ & $11 \mathrm{mo}$ \\
\hline 5 & Mixed breed pony & F $5 \mathrm{yr}$ & $>2 w$ & $\begin{array}{l}\text { Fucidic acid }>1 \mathrm{~W}, \\
\text { chloramphenicol + } \\
\text { autologous } \\
\text { serum in EDTA } 1 \mathrm{w}\end{array}$ & $4 \times 4 \mathrm{~mm} ; 1 / 35 \times 5 \mathrm{~mm} ; 2 / 3$ & no & $\begin{array}{l}\text { Two stromal ulcers in large } \\
\text { superficial ulcer. Severe } \\
\text { purulent discharge }\end{array}$ & No bacteria/ No growth & $9 d+16 d$ & $9 \mathrm{mo}$ \\
\hline 6 & Miniatur Shetland Pony & F 16 y & $<1 w$ & Fucidic acid $<1 \mathrm{w}$ & $8 \times 8 \mathrm{~mm} ; 2 / 3$ & no & $\begin{array}{l}\text { Stromal ulcer in large } \\
\text { superficial ulcer }\end{array}$ & $\begin{array}{l}\text { Abundant bacteria/ } \\
\text { Untyped G + bacteria }\end{array}$ & $14 d$ & $6 \mathrm{mo}$ \\
\hline 7 & Warmblood Trotter & F $1 \mathrm{mo}$ & $<1 w$ & No & $10 \times 13 \mathrm{~mm} ; 2 / 3$ & yes & $\begin{array}{l}\text { Extensive cellular infiltration. } \\
\text { Severe purulent discharge }\end{array}$ & $\begin{array}{l}\text { Abundant bacteria/ } \\
\text { Pasteurella spp }\end{array}$ & $4 d$ & $5 \mathrm{mo}$ \\
\hline 8 & Welsh Pony & $\mathrm{S} 2 \mathrm{mo}$ & $1 \mathrm{w}$ & Chloramphenicol $1 \mathrm{w}$ & $5 \times 5 \mathrm{~mm} ; 2 / 3$ & no & & $\begin{array}{l}\text { Moderate bacteria/ } \\
\text { Untyped G + coccoid }\end{array}$ & $14 d$ & $5 \mathrm{mo}$ \\
\hline 9 & Welsh Pony & F $15 \mathrm{yr}$ & $1 \mathrm{~d}$ & No & $6 \times 18 \mathrm{~mm} ; 1 / 3$ & yes & Corneal laceration & No bacteria/ No growth & $26 d$ & $5 \mathrm{mo}$ \\
\hline
\end{tabular}

$\mathrm{F}=$ female (mare), $\mathrm{G}=$ gelding, $\mathrm{S}=$ stallion, $\mathrm{d}=$ days, $\mathrm{mo}=$ months, $\mathrm{W}=$ weeks, $y \mathrm{r}=$ years, $1 / 3=$ anterior third of the cornea, $2 / 3=$ middle third of the cornea, $\mathrm{G}+=\mathrm{Gram}$-positive, $\mathrm{B}$-hem $=\mathrm{B}$-hemolytic, enucl = enucleated, $\mathrm{n} / \mathrm{a}=$ not applicable. All horses were affected unilaterally. For horse no 5 , the number of days to fluorescein negativity is listed for each of the two stromal ulcers respectively. 

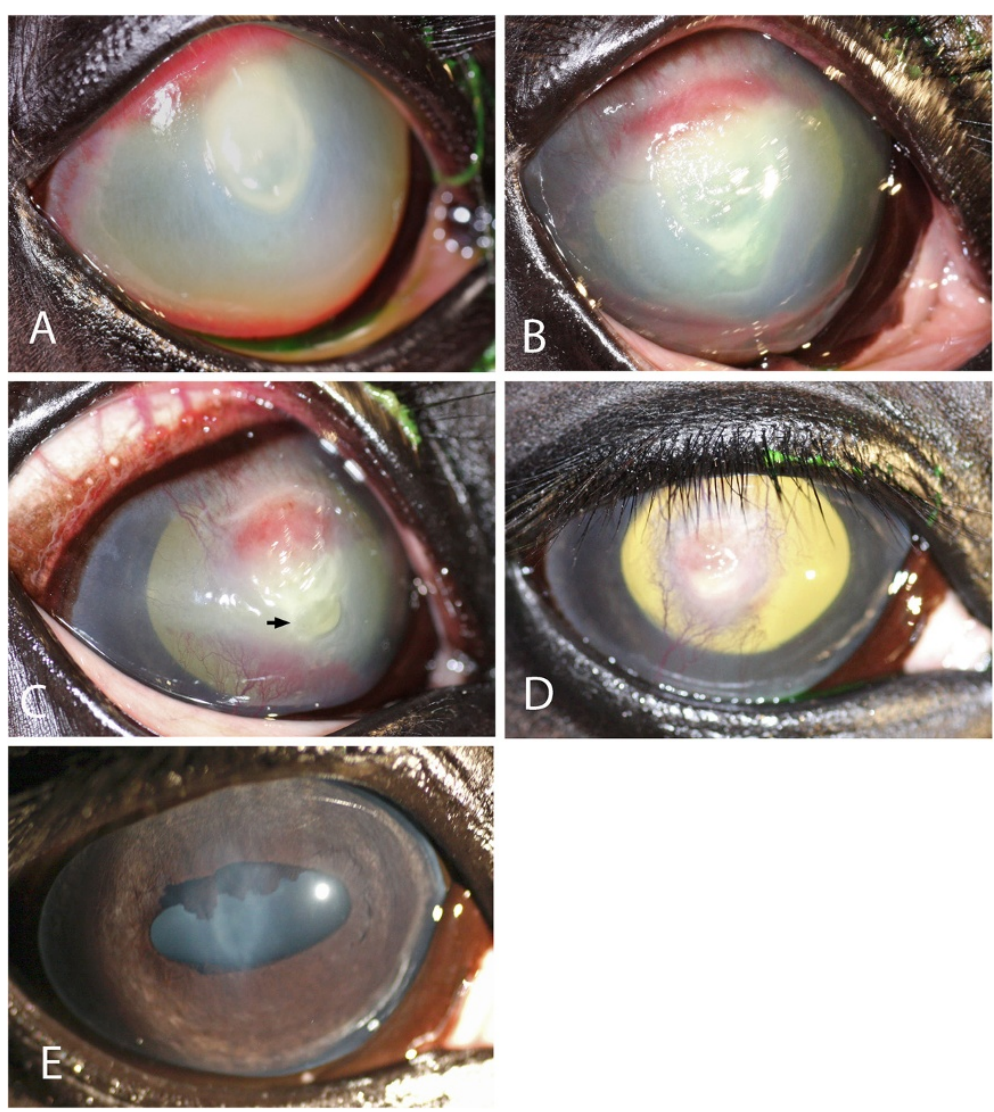

Figure 1 The healing process during follow-up after CXL. A) Horse no. 3 before CXL. This horse had been on topical antibiotic treatment for a stromal ulcer infected by ß-hemolytic streptococci for a week before being referred for CXL. Panels $\mathbf{B}$ ) to $\mathbf{E})$ show the appearance of the cornea from 5 days up to 12 months after $C X L$ in combination with topical and systemic medication $(\mathbf{B})=5, \mathbf{C})=13, \mathbf{D})=20$ days and $\mathbf{E})=12$ months). Notice the formation and rejection of necrotic material (arrow) in the ventral part of the ulcer at 13 days. Scarring is minimal a year after treatment.

alone, but easy to learn and does not require expertise in microsurgery. However, evaluation of pre- and postoperative results should be performed by a person with proper training in equine ophthalmology. Because of the risks associated with general anaesthesia in this species, it is an

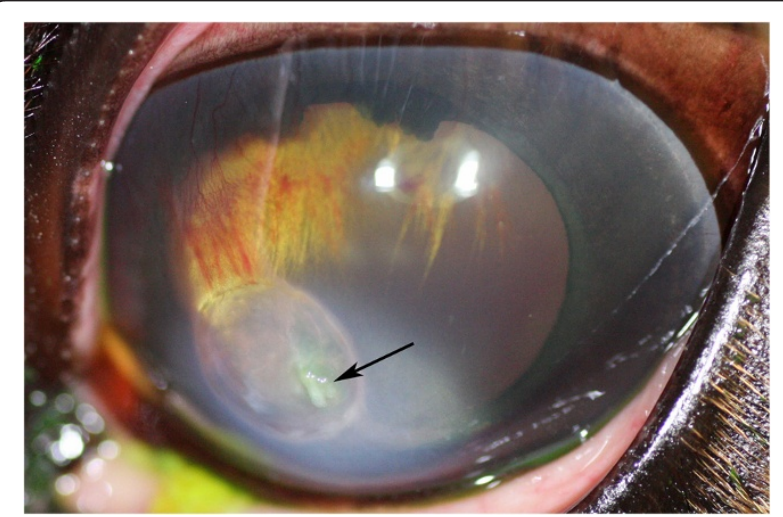

Figure 2 Rejection of necrotic tissue. Rejection of necrotic tissue during healing of the ulcer after 6 days in horse no. 5. The rejection process did not appear to cause discomfort for the patient. advantage to be able to perform the treatment on standing horses under sedation. A stable level of sedation and a calm environment are crucial for proper positioning of the UVA light on the cornea of the horse throughout the procedure.

The melting process seen in four horses had stopped when re-examined the day after treatment. This is in accordance with the results in a pilot study where CXL was used to treat three cats and two dogs with melting corneal ulcers [36], as well as in human patients [17]. CXL is believed to increase the resistance of the cornea to collagen digesting enzymes, because of the structural changes of the collagen fibrils induced by cross-linking $[15,37]$. In the horse, melting of the corneal stroma is not uncommon in patients with corneal ulcers. Frequent instillation of eye drops onto a rapidly melting cornea and painful eye can be rather challenging and certainly time-consuming. The prompt increase in stability of the melting cornea seen in various species suggests that CXL could be beneficial and labour-saving in patients with uncontrolled enzymatic degradation of the corneal stroma. 
Table 2 Median healing time of stromal ulcers

\begin{tabular}{lll}
\hline & CLX - fluorescein neg. [days] & $\begin{array}{c}\text { Onset of clinical signs - } \\
\text { fluorescein neg. [days] }\end{array}$ \\
\hline Horses with and without positive microbial culture $(n=8)$ & $13.5(4-26)$ & $22(10-40)$ \\
Horses with positive microbial culture $(n=6)$ & $11(4-20)$ & $22(10-40)$ \\
\hline
\end{tabular}

The median healing time with ranges. Horse no. 1, which was enucleated, is excluded from the table.

A few days after CXL we observed that the denuded stroma took on a granular appearance in most eyes. This has not been described in other species and might reflect a phase during the post-CXL wound healing that may be specific to the horse. In three horses this was followed by formation of a tissue layer with mucoid, necrotic appearance that was rejected after approximately 1-2 weeks.

Corneal ulcers in the horse often require medical treatment for several weeks and sometimes adjunct corneal surgery [38]. In our study, the median time from CXL to fluorescein negativity was 11 days in horses with positive microbial cultures. Ulcerative keratitis caused by Streptococci is frequently reported to be refractory to treatment, producing stromal melting. Brooks et al. reported an average healing time of $44.7 \pm 26,7$ days in horses with streptococci isolated from corneal ulcers and the vast majority of the horses required corneal surgery [39]. Andrew et al. reported a median duration of treatment of 48 days for 29 horses with ulcerative keratomycosis [40]. In a study by Wada and colleagues, the mean healing time was $38.9 \pm 24.0$ days in 26 horses with positive microbial cultures [2]. Our median healing time is closer to the median time for re-epithelialization reported in human patients with bacterial keratitis primarily treated with CXL (5.5 days; range 1-14 days) [26]. Because of the low number of horses in this study and the absence of a control group, we cannot conclude that the healing time after CXL is different from the time to healing in horses treated medically only.

The CXL was unsuccessful in horse number 1 with fungal keratitis. Light microscopic examination of the globe enucleated four days postoperatively revealed fungal hyphae inside the anterior chamber. At the day of CXLtreatment, but before CXL was performed, this eye showed an aggravation of clinical signs, including hypopyon, pain and miosis. Perhaps the fungi in this case had spread intraocularly already before treatment with CXL. It is also possible that the antifungal effect of the CXL was insufficient, as has been indicated by the work of Martins et al. [22]. Because the antimicrobial effect of CXL is restricted to the superficial $300 \mu \mathrm{m}$ using this type of UVA light source, it is unlikely that microorganisms dwelling deep in the corneal
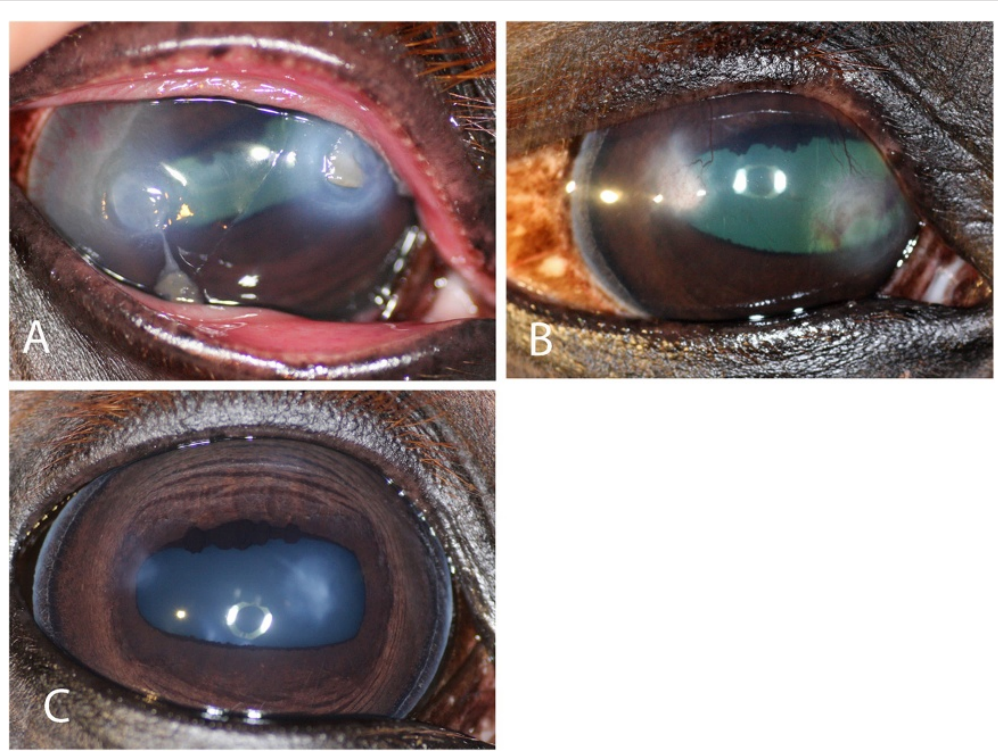

Figure 3 The healing process and follow-up of fungal ulcers after CXL. A) Horse no. 2 presented with 2 stromal ulcers that had been treated for 1 month, initially with topical antibiotics and during the last week before $C X L$, when a diagnosis of fungal ulcerative keratitis was made, with topical natamycin. However, the response was considered poor and CXL was performed. The cornea was fluorescein negative at 9 days after CXL. B) The appearance 30 days and C) 19 months after CXL. 
stroma, would be completely eliminated. Consequently, this case shows that the indications for CXL in the horses with stromal ulcerative keratitis need to be carefully considered.

We experienced one patient that developed a purulent conjunctivitis due to Enterobacter sp. the day after CXL. Enterobacter is known to be an opportunistic species of bacteria not uncommonly isolated from horses with ulcerative keratitis and conjunctivitis $[2,41]$. It is likely that the manipulation of the eye during the examination or treatment of the ulcer played a role in the development of the bacterial conjunctivitis in this horse, but we do not believe that the exposure to the UVA-light or riboflavin eye drops per se caused this problem. Hence, measures to reduce the risk for iatrogenic infections should, as always, be taken and careful postoperative monitoring of the outcome is recommended.

Potential complications of CXL in patients include loss of endothelial cells due to incomplete absorption of the UVA light in the overlying stroma, as well as loss of limbal stem cells after accidental illumination by the UVA light. It has been shown experimentally that CXL of thin corneas or of corneas with insufficient concentration of riboflavin, for instance due to too short exposure to the riboflavin eye drops to allow sufficient absorption, can cause endothelial cell damage $[28,32,42]$. The normal equine cornea is $0.8-1.0 \mathrm{~mm}$ thick [1], therefore, with exception of very deep corneal ulcers, the risk for endothelial damage is judged to be low. To reduce the risk for uncontrolled UV damage to the cornea, we used a light source with an emission spectrum coinciding with the peak absorption of riboflavin in the UVA-part of the spectrum $(365 \mathrm{~nm})$ [43], an optical system providing a rather constant beam intensity across the area illuminated to prevent hot spots and a shutter that allows light-exposure of a well defined area of tissue to avoid incidental damage to limbal stem cells. Furthermore, the radiant exposure and the irradiance used were below the threshold for damaging the human eye by UVA $[28,44]$.

Makdoumi et al., who treated human patients with mainly infectious, ulcerative keratitis, a patient cohort rather similar to our horses, observed no complications that could be attributed to CXL up to 6 months after treatment [26]. We have not observed chronic corneal oedema, which would have been a clinical sign of endothelial decompensation, during the follow up period up to 19 months. Furthermore, light corneal scarring has been reported in a low number of patients with keratoconus treated with CXL [45-47]. Postoperative scarring was present but limited in the 8 horses where CXL was successful in this study and all these horses retained useful vision. Bearing the pre-operative appearance of these corneas, we were impressed with the corneal transparency months after CXL, but again it is not possible to judge whether the CXL treatment has affected the amount of scarring seen postoperatively. However, corneal scarring is considered a problem in equine infectious keratitis no matter whether surgery is performed or not [39].

In summary, vision-threatening complications directly associated with the procedure were not observed in this pilot study. We believe that further studies on CXL in this species are warranted.

\section{Conclusions}

CXL-treatment was readily performed in 9 sedated, standing horses. The median duration from CXL to fluorescein negativity was 13.5 days in the 8 horses where the corneal ulcers healed. Stromal melting seen in 4 horses stopped within $24 \mathrm{~h}$ after CXL. Postoperative corneal scarring was subjectively judged to be light, but comparison to similar ulcers only treated medically was not available. One patient contracted a postoperative, bacterial conjunctivitis and CXL showed no therapeutic effect in one horse. This shows that patients eligible for CXL need to be carefully chosen and monitored postoperatively. We consider CXL potentially useful for treatment of stromal corneal ulcers in the horse, but further research and comparison to conventional medical treatment is needed.

\section{Methods}

\section{Animals}

Nine horses, aged 1 month to 16 years (median 5 years) of different breeds and gender were treated for stromal ulcerative keratitis with CXL using riboflavin and UVAlight during 2010 and 2011 at ATG's Horse Clinic in Skara, Sweden (Table 1). All horses, except for 2 previously untreated horses, were referred because of failure of medical therapy, defined as non-healing ulceration or aggravation of clinical signs from the eye, specifically increased corneal vascularization, oedema, or stromal loss, or emergence of additional ulcers. The two previously untreated horses were included in the study upon request from the owners.

The regional Ethical Committee (Göteborgs Djurförsöksetiska nämnd, Sweden, Dnr 246-2010) approved the use of horses for this study and informed consent was obtained from all horse owners prior to treatment.

\section{Ophthalmic examination}

All horses were examined by the first author before and after the CXL treatment. The horses were sedated and akinesia of the eyelids was induced when needed. The ophthalmic examination included slit-lamp biomicroscopy (Kowa SL15, Kowa Company Ltd, Nagoya, Japan), sampling for cytology and microbiological testing, as well as fluorescein staining. Samples for microbiological cultures and cytology were obtained from the edge of the 
ulcerations using a sterile swab (ESwab, Copan innovation Ltd, Brescia, Italy) and a special brush (Cytology brush Plus, CooperSurgical Inc., Trumbull, USA), respectively. Aerobic bacterial culture and antimicrobial susceptibility testing was performed by a local laboratory (Eurofins, Lidköping, Sweden). Specimens for cytology were stained using May Grünwald Giemsa and Gram staining, respectively. When fungal hyphae were present on cytology, an additional swab was sent for fungal culture. Microbiological cultures and cytology were repeated after CXL in horses nos. 2 and 3 to learn if the microorganisms obtained in the initial samples were eliminated after treatment. All horses were re-examined until the ulcers healed, defined as no fluorescein dye uptake, and absence of clinical signs of pain or anterior uveitis. Photographs of the corneas were taken before CXL and at each reexamination.

The depths of the ulcers were scored according to Burn's system [48]. Only horses with stromal loss comprising $\leq 2 / 3$ of the corneal thickness were included in the study.

The diagnosis of stromal melting was made when the stroma had a gelatinous structure and an abnormal, often drop-shaped contour. When the progressive stromal melting ceased, the structure stabilized and the size of the ulcer stopped increasing.

\section{Sedation, local and topical anesthesia}

The adult horses were sedated with $0.01 \mathrm{mg} / \mathrm{kg}$ detomidine (Domodin vet, $10 \mathrm{mg} / \mathrm{ml}$, Novartis Animal Health, Copenhagen, Denmark) and $0.02 \mathrm{mg} / \mathrm{kg}$ buthorphanol (Butador vet $10 \mathrm{mg} / \mathrm{ml}$, Vetoquinol Scandinavia, Åstorp, Sweden) intravenously. Sedation was maintained throughout the procedure using symptomatic i.v. infusion with $1 \mathrm{mg}$ detomidine per $100 \mathrm{ml}$ physiologic saline solution (Natriumklorid, Fresenius Kabi, Uppsala, Sweden).

The two foals were anesthetized with a combination of $1.0 \mathrm{mg} / \mathrm{kg}$ xylazine (Rompun $20 \mathrm{mg} / \mathrm{ml}$, Bayer Animal Health, Copenhagen, Denmark), $0.05 \mathrm{mg} / \mathrm{kg}$ midazolam (Midazolam $5 \mathrm{mg} / \mathrm{ml}$, Actavis AB, Stockholm, Sweden) and $2.0 \mathrm{mg} / \mathrm{kg}$ ketamine (Ketaminol vet, $100 \mathrm{mg} / \mathrm{ml}$, Intervet $\mathrm{AB}$, Sollentuna, Sweden).

Akinesia of the eyelids was obtained after subcutaneous injection of $1 \mathrm{ml}$ mepivacaine (Carbocain, $20 \mathrm{mg} / \mathrm{ml}$, Astra Zeneca, Södertälje, Sweden) over the auriculopalpebral nerve. The cornea was anesthetized with 2 drops of oxybuprocaine eye drops (Oxibuprokain Chauvin, $20 \mathrm{mg} / \mathrm{ml}$, Bausch \& Lomb Nordic AB, Stockholm, Sweden).

\section{Corneal collagen cross-linking, CXL}

The CXL treatment protocol was based on the protocol developed in Dresden and described by Wollensak et al. in 2003 [33], with minor modifications for horses. Two to $3 \mathrm{~mm}$ of the epithelium surrounding the corneal ulcer was removed using a blunted scalpel blade. Isotonic riboflavin eye drops (Medio-cross ${ }^{\oplus}$, riboflavin $>0.1$ in dextran 500 20\%, Medio-cross GmbH, Neudorf, Germany) were instilled every $2^{\text {nd }}$ minute for 25 minutes. The nonepithelialized part of the cornea was saturated with riboflavin, which could be observed as a yellowish discoloration.

A lid speculum was inserted to keep the eye open during light exposure. Prior to each treatment, the UVAlight source (CCL-365, Peschke Meditrade $\mathrm{GmbH}$, Huenenberg, Switzerland) was calibrated according to the manufacturer's recommendations. The corneal ulcer was then exposed during 30 minutes to a $365 \mathrm{~nm}$ light with an irradiance of $3.0 \mathrm{~mW} / \mathrm{cm}^{2}$ and a beam diameter of $10 \mathrm{~mm}$ (Figure 4). This light source has an optical system that provides a uniform (Köhler) illumination of the treated area [49]. The distance between the UVAlight source and the cornea $(5 \mathrm{~cm})$ was maintained throughout the procedure by supporting the light source by one hand resting against the head of the horse. The light source would then also follow any movements made by the horse and stay centred on the ulcerated area. The operator continuously monitored that the beam remained focused and sharply circumscribed at the corneal surface. Care was taken not to illuminate the limbus with the UV-light.

All horses except horse no. 3 received topical medication after CXL treatment, according to a standard protocol, with $5 \mathrm{ml}$ chloramphenicol eye drops (Chloromycetin, $5 \mathrm{mg} / \mathrm{ml}$, Pfizer AB, Sollentuna, Sweden) and $1 \mathrm{ml}$ atropine eye drops (Isopto-Atropin 1\%, Alcon Sverige AB, Stockholm, Sweden) diluted in autologous serum in 1.8 $\mathrm{mg} / \mathrm{ml}$ EDTA (serum collected in EDTA-tubes) to a total volume of $10 \mathrm{ml}$. This mixture was instilled on the eye

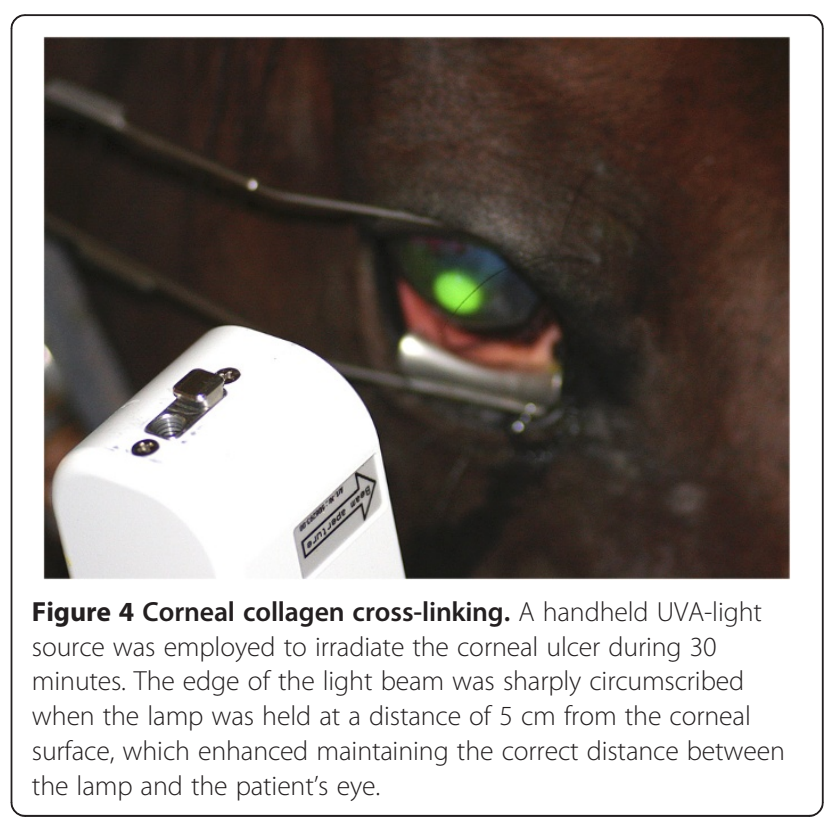


through a continuous delivery system (Infu-Disc ${ }^{\mathrm{Tm}}$, San Diego, CA, USA) at a rate of $0.14 \mathrm{ml} / \mathrm{h}$. Accidently, horse no. 3 got autologous serum and atropine only in the delivery system. To relieve postoperative discomfort and treat concomitant uveitis, $1.1 \mathrm{mg} / \mathrm{kg}$ flunixin meglumine (Cronyxin vet $50 \mathrm{mg} / \mathrm{ml}$, Ceva Animal Health, Lund, Sweden) was given intravenously once daily for 5-8 days in all horses. Horse nos. 3, 7 and 8 were also given penicillin G sodium (Geepenil vet $300 \mathrm{mg} / \mathrm{ml}$, Orion Pharma Animal Health, Sollentuna, Sweden) $14 \mathrm{mg} / \mathrm{kg}$, intravenously q8h, for 6,8 and 4 days respectively.

\section{Statistical analyses}

Medians and ranges are used as descriptive statistics in this study.

\section{Competing interests}

The authors declare that they have no competing interests.

\section{Authors' contributions}

AHE conceived the study, performed ophthalmic examinations and CXL treatments, analysed the data and helped to draft the manuscript. KM provided advice regarding the CXL protocol and helped to draft manuscript. JM proposed the CXL protocol and assisted when CXL was performed. BE helped with the study design, analysis of results and to draft the manuscript. All authors read and approved the final manuscript.

\section{Acknowledgments}

The study was supported by the Swedish-Norwegian Foundation for Equine Research. Peschke Meditrade $\mathrm{GmbH}$ is acknowledged for generously providing a CCL-365 UVA-light source during the study.

\section{Author details}

'Department of Animal Environment \& Health, Swedish University of Agricultural Sciences, PO Box 234, SE-532 24 Skara, Sweden. ${ }^{2}$ Department of Ophthalmology, Örebro University Hospital, SE-701 85 Örebro, Sweden. ${ }^{3}$ Department of Clinical Sciences, Swedish University of Agricultural Sciences, PO Box 7054, SE-750 07 Uppsala, Sweden.

Received: 8 October 2012 Accepted: 13 June 2013

Published: 26 June 2013

\section{References}

1. Brooks DE, Matthews AG: Equine ophthalmology. In Veterinary ophthalmology. Volume II. 4th edition. Edited by Gelatt KN. Ames, IA, USA: Blackwell Publishing Professional; 2007:1192-1211.

2. Wada S, Hobo S, Niwa H: Ulcerative keratitis in thoroughbred racehorses in Japan from 1997 to 2008. Vet Ophthalmol 2010, 13(2):99-105.

3. Johns IC, Baxter K, Booler H, Hicks C, Menzies-Gow N: Conjunctival bacterial and fungal flora in healthy horses in the UK. Vet Ophthalmol 2011, 14(3):195-199.

4. Clode AC, Matthews AG: Diseases and surgery of the cornea. In Equine ophthalmology. 2nd edition. Edited by Gilger BC. Maryland Heights, MO, USA: Elsevier Saunders; 2011:181-215.

5. Moore CP, Collins BK, Fales WH: Antibacterial susceptibility patterns for microbial isolates associated with infectious keratitis in horses - 63 cases (1986-1994). J Am Vet Med Assoc 1995, 207(7):928-933.

6. Sauer $P$, Andrew SE, Lassaline M, Gelatt KN, Denis HM: Changes in antibiotic resistance in equine bacterial ulcerative keratitis (1991-2000): 65 horses. Vet Ophthalmol 2003, 6(4):309-313.

7. Cannon DJ, Davison PF: Aging, and crosslinking in mammalian collagen. Exp Aging Res 1977, 3(2):87-105.

8. Malik NS, Moss SJ, Ahmed N, Furth AJ, Wall RS, Meek KM: Ageing of the human corneal stroma: structural and biochemical changes. Biochim Biophys Acta 1992, 1138(3):222-228.
9. Baier J, Maisch T, Maier M, Engel E, Landthaler M, Bäumler W: Singlet oxygen generation by UVA light exposure of endogenous photosensitizers. Biophys J 2006, 91(4):1452-1459.

10. McCall AS, Kraft S, Edelhauser HF, Kidder GW, Lundquist RR, Bradshaw HE, Dedeic Z, Dionne MJC, Clement EM, Conrad GW: Mechanisms of corneal tissue cross-linking in response to treatment with topical riboflavin and long-wavelength ultraviolet radiation (UVA). Invest Ophthalmol Vis Sci 2010, 51(1):129-138.

11. Kohlhaas M, Spoerl E, Schilde T, Unger G, Wittig C, Pillunat LE: Biomechanical evidence of the distribution of cross-links in corneastreated with riboflavin and ultraviolet A light. J Cat Ref Surg 2006, 32(2):279-283.

12. Spoerl $\mathrm{E}$, Huhle M, Seiler T: Induction of cross-links in corneal tissue. Exp Eye Res 1998, 66(1):97-103.

13. Spörl E, Huhle M, Kasper M, Seiler T: Erhöhung der Festigkeit der Hornhaut durch Vernetzung. Ophthtalmologe 1997, 94(12):902-906.

14. Wollensak G, Spoerl E, Seiler T: Stress-strain measurements of human and porcine corneas after riboflavin-ultraviolet-A-induced cross-linking. J Cat Ref Surg 2003, 29(9):1780-1785.

15. Spoerl $E$, Wollensak $G$, Seiler T: Increased resistance of crosslinked cornea against enzymatic digestion. Curr Eye Res 2004, 29(1):35-40.

16. Snibson GR: Collagen cross-linking: a new treatment paradigm in corneal disease - a review. Clin Experiment Ophthalmol 2010, 38(2):141-153.

17. Muller L, Thiel MA, Kipfer-Kauer Al, Kaufmann C: Corneales Crosslinking als zusätzliche Therapieoption bei einschmelzender Hornhaut: eine FallSerie [Corneal cross-linking as supplementary treatment option in melting keratitis: a case series]. Klin Monatsbl Augenh 2012, 229(4):411-415.

18. Corbin F: Pathogen inactivation of blood components: current status and introduction of an approach using riboflavin as a photosensitizer. Int J Hematol 2002, 76:253-257.

19. Douki T, Cadet J: Modification of DNA bases by photosensitized oneelectron oxidation. Int J Radiat Biol 1999, 75(5):571-581.

20. Tsugita A, Okada Y, Uehara K: Photosensitized inactivation of ribonucleic acids in the presence of riboflavin. Biochim Biophys Acta 1965, 103(2):360-363.

21. Makdoumi K, Bäckman A, Mortensen J, Crafoord S: Evaluation of antibacterial efficacy of photo-activated riboflavin using ultraviolet light (UVA). Graefes Arch Clin Exp Ophthalmol 2010, 248(2):207-212.

22. Martins SAR, Combs JC, Noguera G, Camacho W, Wittmann P, Walther R, Cano M, Dick J, Behrens A: Antimicrobial efficacy of riboflavin/UVA combination $(365 \mathrm{~nm})$ in vitro for bacterial and fungal isolates: a potential New treatment for infectious keratitis. Invest Ophthalmol Vis Sci 2008, 49(8):3402-3408.

23. Iseli HP, Thiel MA, Hafezi F, Kampmeier J, Seiler T: Ultraviolet A/riboflavin corneal cross-linking for infectious keratitis associated with corneal melts. Cornea 2008, 27(5):590-594.

24. Morén H, Malmsjö M, Mortensen J, Öhrström A: Riboflavin and ultraviolet A collagen crosslinking of the cornea for the treatment of keratitis. Cornea 2010, 29(1):102-104.

25. Schnitzler E, Spörl E, Seiler T: [Irradiation of cornea with ultraviolet light and riboflavin administration as a new treatment for erosive corneal processes, preliminary results in four patients]. Klin Monatsbl Augenh 2000, 217(3):190-193.

26. Makdoumi K, Mortensen J, Sorkhabi O, Malmvall B-E, Crafoord S: UVA-riboflavin photochemical therapy of bacterial keratitis: a pilot study. Graefes Arch Clin Exp Ophthalmol 2012, 250(1):95-102.

27. Makdoumi K: Ultraviolet light (UVA) photoactivation of riboflavin as a potential therapy for infectious keratitis. PhD. Örebro: Örebro University; 2011.

28. Spoerl E, Mrochen M, Sliney D, Trokel S, Seiler T: Safety of UVA-riboflavin cross-linking of the cornea. Cornea 2007, 26(4):385-389.

29. Dhaliwal JS, Kaufman SC: Corneal collagen cross-linking: a confocal, electron, and light microscopy study of eye bank corneas. Cornea 2009, 28(1):62-67.

30. Wollensak G, Spoerl E, Reber F, Seiler T: Keratocyte cytotoxicity of riboflavin//UVA-treatment in vitro. Eye 2004, 18(7):718-722.

31. Wollensak G, Spoerl E, Wilsch M, Seiler T: Keratocyte apoptosis after corneal collagen cross-linking using riboflavin/UVA treatment. Cornea 2004, 23(1):43-49.

32. Wollensak G, Spoerl E, Wilsch M, Seiler T: Endothelial cell damage after riboflavin-ultraviolet-A treatment in the rabbit. J Cat Ref Surg 2003, 29(9):1786-1790. 
33. Wollensak G, Spoerl E, Seiler T: Riboflavin/ultraviolet-a-induced collagen crosslinking for the treatment of keratoconus. Am J Ophthalmol 2003, 135(5):620-627.

34. Wollensak G, lomdina E, Dittert D-D, Herbst H: Wound healing in the rabbit cornea after corneal collagen cross-linking with riboflavin and UVA. Cornea 2007, 26(5):600-605.

35. Mazzotta C, Traversi C, Baiocchi S, Caporossi O, Bovone C, Sparano MC, Balestrazzi A, Caporossi A: Corneal healing after riboflavin ultraviolet-A collagen cross-linking determined by confocal laser scanning microscopy in vivo: early and late modifications. Am J Ophthalmol 2008 146(4):527-533. e521.

36. Pot S, Florin M, Spiess B, Hafezi F: Treatment of "melting" ulcers in dogs and cats with UV-A/riboflavin cross-linking of corneal collagen (CXL): a pilot study. Vet Ophthalmol 2011, 14(4):281.

37. Berman MB: Collagenase inhibitors: rationale for their Use in treating corneal ulceration. Int Ophthalmol Clin 1975, 15(4):49-66.

38. Brooks DE: Ophthalmology for the equine practitioner. Jackson, WY, USA Teton NewMedia; 2002

39. Brooks DE, Andrew SE, Biros DJ, Denis HM, Cutler TJ, Strubbe DT, Gelatt KN: Ulcerative keratitis caused by beta-hemolytic Streptococcus equi in 11 horses. Vet Ophthalmol 2000, 3(2-3):121-125.

40. Andrew SE, Brooks DE, Smith PJ, Gelatt KN, Chmielewski NT, Whittaker CJG Equine ulcerative keratomycosis: visual outcome and ocular survival in 39 cases (1987-1996). Equine Vet J 1998, 30(2):109-116.

41. Barnett KC, Crispin SM, Lavach JD, Matthews AG: Equine ophthalmology: an atlas \& text. 2nd edition. Oxford, UK: Elsevier Ltd: 2004:98-125.

42. Wollensak G, Spörl E, Reber F, Pillunat L, Funk R: Corneal endothelial cytotoxicity of riboflavin/UVA treatment in vitro. Ophthalmic Res 2003, 35(6):324-328.

43. Kurtin WE, Song P-S: Photochemistry of the model phototropic system involving flavins and indoles $-I$. Fluorescence polarization and $\mathrm{MO}$ calculations of the direction of the electronic transition moments in flavins. Photochem Photobiol 1968, 7(3):263-273.

44. Goldich Y, Marcovich AL, Barkana Y, Avni I, Zadok D: Safety of corneal collagen cross-linking with UV-a and riboflavin in progressive keratoconus. Cornea 2010, 29(4):409-411.

45. Hovakimyan M, Guthoff RF, Stachs O: Collagen cross-linking: current status and future directions. J Ophthalmol 2012, article ID 406850.

46. Koppen C, Vryghem JC, Gobin L, Tassignon M-J: Keratitis and corneal scarring after UVA/riboflavin cross-linking for keratoconus. J Refract Surg 2009, 25(9):S819-S823.

47. Koller T, Mrochen $\mathrm{M}$, Seiler $\mathrm{T}$ : Complication and failure rates after corneal crosslinking. J Cat Ref Surg 2009, 35(8):1358-1362.

48. Burns FR, Gray RD, Paterson CA: Inhibition of alkali-induced corneal ulceration and perforation by a thiol peptide. Invest Ophthalmol Vis $\mathrm{SC}$ 1990, 31(1):107-114

49. Köhler A: Ein neues Beleuchtungsverfahren fur mikrophotographische Zwecke. Zeitschrift fur wissenschaftliche Mikroskopie und fur Microscopische Technik 1893, 10(4):433-440.

doi:10.1186/1746-6148-9-128

Cite this article as: Hellander-Edman et al: Corneal cross-linking in 9

horses with ulcerative keratitis. BMC Veterinary Research 2013 9:128.

\section{Submit your next manuscript to BioMed Central and take full advantage of:}

- Convenient online submission

- Thorough peer review

- No space constraints or color figure charges

- Immediate publication on acceptance

- Inclusion in PubMed, CAS, Scopus and Google Scholar

- Research which is freely available for redistribution

Submit your manuscript at www.biomedcentral.com/submit
Ciomed Central 